Dorota KLIMEK-JANKOWSKA

ORCID: 0000-0003-3102-1384

Uniwersytet Wrocławski

Joanna BŁASZCZAK ${ }^{*}$

ORCID: 0000-0002-8332-2827

Uniwersytet Wrocławski
Edyta BŁACHUT

ORCID: 0000-0001-9234-465X

Uniwersytet Wrocławski

Zuzanna CZERWONKA-WAJDA

ORCID: 0000-0003-2578-1387

Uniwersytet Wrocławski

\title{
Anna BORKOWSKA
}

ORCID: 0000-0001-5428-0974

Uniwersytet Wrocławski

\section{Grammatical gender and stereotypical gender associations with inanimate nouns in the 'Germanic sandwich'}

\begin{abstract}
This pilot study is a contribution to the theoretical debate on the impact language has on general cognition. More specifically, we applied a Word Sketch collocator (an innovative NLP tool operating on large-scale corpora) to collect human adjective collocations of masculine, feminine, and neuter inanimate nouns in German, Dutch, and English to see whether there is a correlation between the grammatical genders of inanimate nouns and the adjective collocations most frequently used to describe those nouns. Later, in a series of online questionnaires, we examined the impact of grammatical gender and stereotypical gender associations on the perception of inanimate nouns (e.g., street, lamp, bottle) by testing the gender associations of their human adjective collocations obtained from the Word Sketch collocator in German (a grammatical gender language), Dutch (a language with a combination of grammatical gender and natural gender), and English (a natural gender language). In German, the results show that grammatical gender alone is not a decisive factor in causing masculine or feminine gender associations of inanimate nouns. Rather, it is the combination of grammatical gender and stereotypical gender associations of nouns that plays a role. In English, nouns associated with neutral, masculine and even feminine gender had significantly more neutral adjectival associations. In Dutch, nouns with common and neuter gender resulted in a higher proportion of masculine adjectival associ-
\end{abstract}

* This paper is dedicated to the memory of our dear friend Joanna Błaszczak, who passed away while this paper was being peer-reviewed. 
ations because these nouns are mostly referred to with common and masculine pronouns. We observed a special role played by stereotypical feminine associations of nouns in German, Dutch, and English.

Keywords: grammatical gender, gender perception, human adjective collocations, inanimate nouns, German, Dutch, English.

\section{Introduction}

In this pilot study we combine two independent lines of research on grammatical gender. On the one hand, there is a growing interest in the grammatical gender systems of the so-called 'Germanic sandwich' comprising German, Dutch and English, which have retained grammatical gender distinctions to varying degrees in the course of their development (see Audring 2006). On the other hand, there is a lot of interest in whether the grammatical gender of inanimate nouns can affect whether they are perceived as more feminine, masculine or gender neutral (see for example Mickan et al. 2014; Vigliocco et al. 2005; Boroditsky et al. 2003; Cubelli et al. 2011; Boutonnet et al. 2012; Segel and Boroditsky 2011; Sera et al. 1994; Haertlé 2017).

The comparison of English, German, and Dutch has a well-established tradition in Dutch linguistics with a starting point in 1956 when van Haeringen's book on comparative linguistics, Nederlands tussen Duits en Engels ('Dutch between German and English') was published. Van Haeringen (1956) observed that Dutch holds the middle position between German and English. Audring (2006) points out that the gender system of the Germanic languages originally had three values: masculine, feminine and neuter, but that in the course of their development some of the languages have lost some of their gender markers. Now German, Dutch and English represent three stages in this development: while German has retained the original three-gender system, contemporary Standard Dutch no longer distinguishes between masculine and feminine nouns and English has lost the nominal gender distinctions entirely (Audring 2006; also see De Vogelaer et al. 2020).

Independently, Boroditsky et al. (2003) and later numerous studies (Mickan et al. 2014; Vigliocco et al. 2005; Boroditsky et al. 2003; Cubelli et al. 2011; Boutonnet et al. 2012; Segel and Boroditsky 2011; Sera et al. 1994; Haertlé 2017) showed that differences in the grammatical gender coding of nouns affect the speaker's mental representations of the objects to which they refer. More specifically, inanimate nouns which are grammaticalised as masculine or feminine in grammatical gender languages are more likely to trigger stereotypical masculine or feminine associations than the corresponding nouns in English which are not morphologically marked for grammatical gender (cf. Mickan et al. 2014¹). A modified view

${ }^{1}$ For failures to replicate, see Mickan et al. 2014. However, as the authors admit, they were not able to properly replicate Boroditsky et al. 2003, because the procedures used in their study were not described in enough detail. 
was proposed by Chłopek (2013), who also studied the impact of the grammatical gender of inanimate nouns on how they are conceptualised in the minds of German-English-Polish multilingual speakers. The author suggested that the gender perception of inanimate objects is not only affected by their grammatical gender, but also by the stereotypical associations triggered by such objects.

We contribute to this debate by testing gender associations of adjectival human collocations of inanimate nouns in German (a grammatical gender language), Dutch (a language with a combination of grammatical gender and natural gender) and English (a natural gender language) using the online collocator Word Sketch (an innovative NLP tool operating on large-scale corpora; Kilgarriff et al. 2014). We hypothesise that human adjective collocations of inanimate nouns can reveal whether native speakers (language users whose first language is German, Dutch or English) conceptualise these nouns as more feminine, masculine or neutral. To test this hypothesis, we created a list of feminine, masculine and neuter nouns in German and their Dutch and English equivalents. German, being the most marked for grammatical gender, served as the point of reference in our comparative study. We balanced the number of inanimate nouns of each gender which are in our opinion $^{2}$ stereotypically associated with masculine features, e.g., das Auto 'a car', der Bart 'beard', die Pfeife 'a pipe', feminine features, e.g., die Bluse 'a blouse', der Ring 'a ring', das Bügeleisen 'an iron' and those which trigger no stereotypical gender associations, e.g., das Fenster 'a window', die Lampe 'a lamp' and der Kugelschreiber 'a pen'. We collected human adjective collocations of the selected nouns using the Word Sketch application (available at http://www.sketchengine. eu; Kilgarriff et al. 2014). Finally, using an online questionnaire we tested native speakers' stereotypical associations evoked by these adjective collocations for the classes of nouns being tested. ${ }^{3}$

Before describing our study in Section 3, we provide relevant background related to the gender systems of German, Dutch and English (Section 2.1) as well as a brief summary of previous literature on the role grammatical gender and stereotypical gender associations of inanimate nouns on their perception by native speakers (Section 2.2). The main findings of our study are summarised in the conclusion in Section 5.

2 It should be noted that in future research it will be necessary to carry out an additional survey confirming that the stimuli in each condition are stereotypically associated with masculine or feminine gender or are gender neutral. In this pilot study, the selection of stimuli in each condition was based on the subjective evaluation of the authors of this study, which constitutes a limitation.

${ }^{3}$ In our online questionnaire entitled 'Adjective gender associations' participants were given a list of adjectives. Their task was to decide whether they associated each of the adjectives with a feminine $(\mathrm{F})$, masculine $(\mathrm{M})$ or neutral $(\mathrm{N})$ gender. The survey was anonymous. More information about the methodology that was used is available in Section 3.1. 


\section{Theoretical background}

\subsection{The gender systems of German, Dutch and English}

In languages with nominal gender distinctions, each noun belongs to a certain gender and this is invariant in the sense that speakers cannot change the gender of a noun by using different gender markers in the same way that they can change the grammatical number of a noun by marking it with either singular or plural morphology. German, with three genders (masculine, feminine and neuter), is classified by Gygax et al. (2019), as a grammatical gender language. In German, gender is an inherent category of a noun (cf. Duden 2016; Eisenberg 2006). Dutch is classified by Gygax et al. (2019) as a language with a combination of grammatical gender and natural gender because human nouns in Dutch have no formal distinction between masculine and feminine forms, but inanimate nouns are morphologically marked for two genders: common and neuter. Common gender is a conflation of former masculine and feminine gender dating back to the seventeenth century (Geerts 192-210). Whereas Standard Dutch does not distinguish between feminine and masculine nouns (cf. de man 'man', de vrouw 'woman'), this distinction is still preserved in several Eastern and Southern Dutch dialects and features prominently in Flemish. English is classified by Gygax et al. (2019) as a natural gender language as it no longer has a nominal gender, but it does have gender distinctions in pronouns (cf. Corbett 1991).

All genders in German (masculine, feminine and neuter) are formally expressed mainly by determiners, e.g., by the definite article (der, die, das). Gender assignment to the majority of Dutch nouns does not follow any formal or semantic criteria, but is arbitrary (see Kraaikamp 2017 for an overview). In Dutch, only two articles (de, het) mark the gender of the nouns. De used with masculine and feminine nouns often leaves the gender distinction ambiguous. For example, de zon 'the sun' and de maan 'the moon' are feminine, but they are preferably used as masculine and referred to by means of the pronoun hij 'he'. Interestingly, as pointed out in Kraaikamp (2017), common and masculine pronouns are used with referents with a high degree of individuation (concrete objects), while neuter pronouns are used with referents with a low degree of individuation (materials and liquids). In English, the articles (a/an, the) do not indicate the gender of a noun; the gender is usually expressed via pronouns (he, she, it; his, her, its).

In the next sections, we will focus on how this varying degree of grammaticalisation of grammatical gender in German, Dutch and English can contribute to a better understanding of the interaction between grammatical gender and stereotypical gender-related associations of inanimate nouns. 


\subsection{Grammatical gender of inanimate nouns and their mental representations}

It has been claimed by various scholars that the structure of one's first language may shape a person's thoughts. In 1956, Whorf argued that it was so influential that it caused speakers of different languages to perceive the world differently.

Several studies have attempted to find out how the differences in grammatical gender coding of nouns affect the speakers' mental representations of objects to which they refer. For instance, Jakobson (1966) recalls some of the early research on this issue in which participants were told to personify days of the week (237). They showed a strong tendency to choose the gender of the personifications which could be compatible with the grammatical gender of the days' names (the participants personified Monday marked for masculine gender as a male and Wednesday marked for feminine gender as a female). Konishi on the other hand examined speakers' assessments of nouns in terms of potency, a quality strongly associated with being masculine. Grammatically masculine nouns obtained significantly higher ratings than feminine nouns, both in German and Spanish.

In this vein, Boroditsky et al. (2003) conducted a series of experiments to provide further evidence that the grammatical gender of inanimate nouns can influence their mental representations. They focused on the effects observed in linguistic and non-linguistic tasks performed in a foreign language. Their research question was whether the mental representations of objects were shaped primarily by one's L1 (first language). If so, this would mean that associations stemming from grammatical gender marking are active regardless of the linguistic nature of the thought processes operating at a given moment.

In the first two experiments, Boroditsky et al. (2003) investigated Spanish and German speakers performing linguistic tasks in English. All of the items had names with opposite grammatical genders in Spanish and German. In one experiment, the participants were taught proper names assigned to 24 inanimate objects. Later, they were asked to recall those names in a memory test. The subjects performed well in the trials where the name was compatible with the grammatical gender of the corresponding noun in their native tongue. When the name was incompatible, their performance was significantly worse. In the second experiment, the researchers had their participants describe a list of objects with the first adjectives that came into their minds. Feminine item names were consistently described with feminine adjectives and masculine item names were described with adjectives that were masculine in the subjects' native languages. Both experiments showed that in a linguistic task, even when one uses a foreign language, the grammatical gender of nouns in their native language influences the speakers' perception of the objects to which the nouns refer. These results were later confirmed in a series of experi- 
ments conducted mainly for Romance languages. Vigliocco et al. (2005) report the results of two experiments in which they tested whether the grammatical gender of Italian nouns referring to animals and tools affects the conceptual representations of the objects being described. They observed an effect of grammatical gender in Italian but not in English, and only for animals (not for tools). Cubelli et al. (2011) conducted three semantic categorisation experiments in which they examined the impact of grammatical gender on object categorisation in monolingual speakers of English, Italian and Spanish. They observed that Italian and Spanish participants (in contrast to English participants) responded faster to pairs of nouns of the same gender. In their ERP study, Boutonnet et al. (2012) investigated whether grammatical gender modulates the perception and categorisation of everyday objects. They compared Spanish-English bilingual speakers with native speakers of English in a semantic categorisation task with triplets of pictures. The results of their study showed the expected semantic priming effect in both groups of participants, but they additionally report a negative modulation by gender inconsistency only in Spanish-English bilingual speakers. These results provide evidence for linguistic relativity effects. Segel and Boroditsky (2011) analysed works of art in the ARTstor database (a digital art library containing over a million images) and they showed a clear correlation between grammatical gender encoding in a given language and the way artists personified gender in art. Grammatical gender predicted personified gender in $78 \%$ of the cases. Sera et al. (1994) compared the assignment of gender to masculine and feminine objects (classified according to the grammatical gender of Spanish nouns) by English and Spanish children and adults. They provide evidence that speakers of Spanish began to classify objects according to grammatical gender in the second grade of school, unlike speakers of English. Haertle (2017) reports the results of a study on gender categorisation of nouns depending on their grammatical gender in Polish and French, showing that grammatical gender may cue people objects as masculine or feminine.

A slightly different conclusion was reached by Chłopek (2013), whose study is about Polish-English multilinguals. Chłopek's (2013) study is discussed in more detail in the next section.

\subsection{Gender system, conceptual system and gender associations of inanimate nouns}

Chłopek (20213) investigated the relation between the language system and the conceptual system. More precisely, her study addressed the question of whether a conceptual transfer related to the perceived gender of objects is possible. In order to answer this question, Chłopek (2013) conducted an experiment with 80 Polish native speakers. In addition to having L1 Polish and L2 German, all the participants also had L3 English competence. The participants were presented with seven 
different objects (whose gender was different in Polish and German) and were asked to finish the incomplete drawings of those objects and to give the English name for each of them. The experiment was conducted in English in order to activate the participants' L3 and immediately after a German class in order to activate their L2 and at the same time to decrease the possible influence of the L1 gender on the participants' answers. The results of the study confirmed that the conceptual system is determined by a speaker's L1 and that L1 categories are also activated when another language (here: L3 English) is used. Furthermore, Chłopek's (2013) study showed that what is also relevant for the conceptual system are associations. For example, two objects ('tower' and 'bone') were perceived in accordance not with the feminine gender of the Polish counterparts of these objects (cf. wieza-F and $k o s^{\prime} c^{-}-\mathrm{F}$ ) but seemingly with the masculine German gender of such objects (cf. Turm-M and Knochen-M). The author suggested that the gender perception in these two cases might have to do with specific associations triggered by the objects in question: the tower was associated with medieval warriors (masculine in Polish) and the bone was associated with a dog (masculine in Polish). This shows that further studies on gender perception are needed. In particular, more research is needed to test whether there is an interaction between the grammatical gender of inanimate nouns and their gender-related stereotypical associations. The study reported below set out to address this issue using innovative NLP tools operating on large-scale corpora. More specifically, we applied a Word Sketch collocator (Kilgarriff et al. 2014) to collect human adjective collocations of masculine, feminine and neuter inanimate nouns in German, Dutch and English to see whether there is a correlation between the grammatical genders of inanimate nouns and the adjective collocations most frequently used to describe those nouns. This methodological trend is quite novel in research on the impact of the grammatical gender of nouns on the stereotypical gender associations of the corresponding adjectives and has already delivered some promising results in the preliminary research of Williams et al. (2021).

\section{Methods}

\subsection{Material, procedures and participants}

The goal of our pilot study was to test stereotypical gender associations of adjectival human collocations of inanimate nouns in German (a grammatical gender language), Dutch (a language with a combination of grammatical gender and natural gender) and English (a natural gender language). To achieve this goal we created a list of feminine, masculine and neuter nouns in German and their Dutch and English equivalents (see Appendix 1). We decided to use German as our point of reference since it has the richest gender system. We created a list 
of German nouns (15 of each grammatical gender). Within each group of 15 nouns 5 were stereotypically associated with feminine gender, 5 with masculine gender and 5 were not associated (neutral). Next, we created a list of the Dutch and English counterparts of these nouns. In Dutch and English the number of items semantically associated with feminine, masculine gender and neutral was the same as in German. After this, we collected human adjective collocations for all the German, Dutch and English nouns on our list using a Word Sketch application embedded under Sketch Engine available at http://www.sketchengine.eu; (Kilgarriff et al. 2014); ${ }^{4}$ see Tables 1, 2 and 3. A collocation is a combination of words that co-occur more often than would be expected by chance. Collocations may differ in strength. The strength of collocations in Word Sketch is expressed by the $\log$ Dice score. For each of the nouns included in our German, Dutch and English list we searched for adjective collocations and selected only those which could be used to describe humans. The decisive criterion was whether a given adjective could be used in the phrase $a$........ person. Additionally, we included only those adjective collocations which described permanent qualitative features. Hence, classifying adjectives describing race, nationality, skin or hair colour, as well as those describing temporary traits were not included in our final list of human adjective collocations. Finally, we tested native speakers' gender associations evoked by the adjectives in the test in the form of an online questionnaire. The participants (20 native speakers of German, 20 native speakers of Standard Dutch from the Netherlands and 20 native speakers of British English, all of them university students) $)^{5}$ saw an adjective in their native language and were asked to decide if it is stereotypically associated with feminine, masculine or neutral gender.

Our research question was to what degree adjective collocations of inanimate nouns in German, Dutch and English are stereotypically associated with feminine or masculine biological gender depending on the gender systems of the languages being tested, as suggested by Boroditsky et al. (2003), or whether they are influenced by the conceptual semantics of the selected nouns, with some of them being more stereotypically associated with feminine or masculine biological gender. The latter result is expected based on the preliminary observations made by Chłopek (2013).

${ }^{4}$ Sketch Engine is an online multilingual tool for the analysis of text from large language corpora. A Word Sketch application searches for collocations of words and organises them into several grammatical relations.

5 The sample size of participants is small because this is a pilot study. Since the results reached statistical significance, it is worth studying this issue this issue on a larger more controlled group of participants. 


\begin{tabular}{|c|c|c|c|}
\hline $\begin{array}{c}\text { Grammatical } \\
\text { gender }\end{array}$ & $\begin{array}{c}\text { Gender } \\
\text { associations }\end{array}$ & Nouns & Collocations \\
\hline feminine & feminine & die Bluse & feminin, modisch, schick, schlicht, zart, hübsch, \\
romantisch
\end{tabular}

Table 1. Selected examples of adjective-noun collocations in German; table created by the authors

\begin{tabular}{|c|c|c|c|}
\hline $\begin{array}{c}\text { Grammatical } \\
\text { gender }\end{array}$ & $\begin{array}{c}\text { Gender } \\
\text { associations }\end{array}$ & Nouns & Collocations \\
\hline common & feminine & de bloes & $\begin{array}{r}\text { chic, dun, nat, mooi, elegant, sexy, trendy, } \\
\text { stijlvol, hip, leuk, simpel, opvallend, vrouwelijk, } \\
\text { eenvoudig, zacht }\end{array}$ \\
\hline common & masculine & de stropdas & $\begin{array}{c}\text { modieus, stijlvol, slank, lelijk, keurig, hip, ele- } \\
\text { gant, formeel, dun, opvallend, dik, fraai, mooi, } \\
\text { stevig, traditioneel, prachtig, gewoon }\end{array}$ \\
\hline common & neutral & de doos & $\begin{array}{r}\text { leeg, nat, oud, origineel, plat, schattig, kaal, } \\
\text { dicht, mooi, chic, zwaar, stijlvol, fraai, blond, } \\
\text { mysterieus }\end{array}$ \\
\hline feminine & de ring & $\begin{array}{r}\text { vals, lang, vol, blond, natuurlijk, dun, sexy, } \\
\text { dik, perfect, extreem, opvallend, kort, prachtig, } \\
\text { zacht, echt, fijn, sterk }\end{array}$ \\
\hline common & masculine & de motor & $\begin{array}{r}\text { krachtig, zuinig, stil, schoon, zwaar, sterk, } \\
\text { lopend, kapot, koud, licht, modern, betrouwbaar, } \\
\text { soepel, conventioneel }\end{array}$ \\
\hline
\end{tabular}




\begin{tabular}{|c|c|c|c|}
\hline neuter & feminine & het tafelkleed & chic, vrolijk, mooi, fraai, dik \\
\hline neuter & masculine & het hemd & $\begin{array}{c}\text { bebloed, stijlvol, schoon, net, perfect, simpel, } \\
\text { lang, open, mooi }\end{array}$ \\
\hline neuter & neutral & het bed & $\begin{array}{c}\text { heerlijk, goed, warm, schoon, leeg, ouderlijk, } \\
\text { charmant, fijn, vast, romantisch, smal, echt, } \\
\text { goed, vreemd, massief, fris, gezellig, hard, }\end{array}$ \\
\hline
\end{tabular}

Table 2. Selected examples of adjective-noun collocations in Dutch; table created by the authors

\begin{tabular}{|c|c|c|c|}
\hline $\begin{array}{l}\text { Grammatical } \\
\text { gender }\end{array}$ & $\begin{array}{c}\text { Gender } \\
\text { associations }\end{array}$ & Nouns & Collocations \\
\hline $\begin{array}{l}\text { not available } \\
\text { (n.a.) }\end{array}$ & feminine & blouse & $\begin{array}{l}\text { gorgeous, lovely, beautiful, perfect, popular, } \\
\text { amazing }\end{array}$ \\
\hline n.a. & masculine & tie & $\begin{array}{l}\text { formal, strong, cool, slim, weak, rare, alive, } \\
\text { thin, super, ideal, solid, nice, short, powerful, } \\
\text { fantastic }\end{array}$ \\
\hline n.a. & neutral & can & $\begin{array}{l}\text { great, cool, valuable, ideal, clean, small, proud, } \\
\text { popular, big, successful, good, happy }\end{array}$ \\
\hline n.a. & feminine & ring & $\begin{array}{l}\text { big, bright, lovely, cute, magical, gorgeous, } \\
\text { beautiful, stunning, thin, elegant, perfect, nice, } \\
\text { fantastic, unique, special, ideal, wonderful, } \\
\text { amazing, attractive, dangerous, hot }\end{array}$ \\
\hline n.a. & masculine & engine & $\begin{array}{l}\text { friendly, powerful, idle, noisy, cold, reliable, } \\
\text { warm, loud, hot, smart, sophisticated, silent, } \\
\text { clean, impressive, flexible, compliant, heavy, } \\
\text { unreliable, cool, good, stationary, superb, popular, } \\
\text { rough, intelligent, solid, small, strong, versatile }\end{array}$ \\
\hline n.a. & neutral & chair & $\begin{array}{l}\text { sturdy, stylish, ideal, perfect, elegant, upright, } \\
\text { gorgeous, lovely, solid, beautiful, fabulous, awe- } \\
\text { some, luxurious, supportive }\end{array}$ \\
\hline n.a. & feminine & tablecloth & fancy, pale, gorgeous, beautiful, clean, perfect \\
\hline n.a. & masculine & shirt & $\begin{array}{l}\text { stylish, cool, sexy, perfect, funny, ugly, ideal, } \\
\text { gorgeous, fantastic, bright }\end{array}$ \\
\hline n.a. & neutral & bed & $\begin{array}{c}\text { sturdy, ideal, clean, perfect, nice, big, huge, } \\
\text { gorgeous, cold, modern, adorable, large, small, } \\
\text { beautiful, cute, awesome, cool, elegant, thin, } \\
\text { versatile }\end{array}$ \\
\hline
\end{tabular}

Table 3. Selected examples of adjective-noun collocations in English; table created by the authors

\subsection{Hypotheses}

If it is true that the grammatical gender of inanimate nouns may affect the type of adjectives with which they collocate (based on Boroditsky et al. 2003): 
We expect that grammatically feminine and masculine inanimate nouns in German should have more adjective collocations stereotypically associated with feminine and masculine features than their English equivalents, since English inanimate nouns are gender neutral. It is also predicted that grammatically neuter nouns in German should have fewer adjective collocations associated with feminine and masculine gender features than grammatically feminine and masculine nouns.

As far as Dutch is concerned, common gender inanimate nouns (comprising masculine and feminine nouns) should have more adjective collocations stereotypically associated with feminine and masculine genders than neutral associations. By contrast, for neuter nouns, we expect more gender neutral adjective collocations than collocations specifically associated with feminine and masculine gender.

With regard to English, given its lack of grammatical gender, we expect to find more neutral adjective associations than in Dutch and German.

If it is true that stereotypical gender associations of inanimate nouns may affect the type of adjectives with which they collocate (based on Chłopek 2013):

We expect that the stereotypical gender associations of inanimate nouns will affect the proportion of adjective gender associations independently of their grammatical gender within each of the languages being tested: German, Dutch and English.

Finally, if both factors (grammatical gender and stereotypical associations of inanimate nouns with feminine or masculine gender) have an impact on the number of adjective collocations stereotypically associated with a given gender:

We expect an interaction between these factors. More specifically, if the grammatical gender of a given inanimate noun matches its stereotypical gender association, we expect a positive correlation (an enhanced proportion of gender associations of adjective human collocations corresponding to a given grammatical gender). Conversely, if the grammatical gender of a given inanimate noun does not match its stereotypical gender association, we expect a negative correlation (a lower proportion of gender associations of adjective human collocations corresponding to a given grammatical gender).

\subsection{Statistical analysis and results}

Loglinear analysis using the loglm function from MASS Ripley, Venables, Bates et al. package was carried out to determine the significance of the effects of grammatical gender, gender association and cross-linguistic differences between German, English and Dutch. The significance of main effects and interaction effects was estimated using log-likelihood on model comparison. Significance of interaction and main effects were determined by subtracting the effect of interest from a model and comparing this model to the model with all the main and interaction effects. The final model retained the three-way interaction effect (grammatical 
gender $\mathrm{x}$ gender association $\mathrm{x}$ language $)(\chi 2(16)=46.1308, \mathrm{p}<0.0001) .{ }^{6}$ This effect is presented graphically in Figure 1 . The horizontal axis shows three grammatical genders in German: FEMININE, MASCULINE and NEUTER. The vertical axis shows three types of gender associations for the nouns being tested: FEMININE, MASCULINE and NEUTRAL. Finally, the abbreviated forms FEM, MASC, NEUT correspond to the proportions of gender associations provided by our respondents for the adjective collocations that were tested. Boxes shaded in dark blue indicate statistically significant positive associations $(\mathrm{p}<0.01)$, whereas boxes shaded in dark red indicate statistically significant negative associations $(\mathrm{p}<0.01)$. The size of the boxes illustrates the proportions of the relevant categories.

Threeway interaction effect: grammatical gender $\mathrm{x}$ gender association $\mathrm{x}$ language

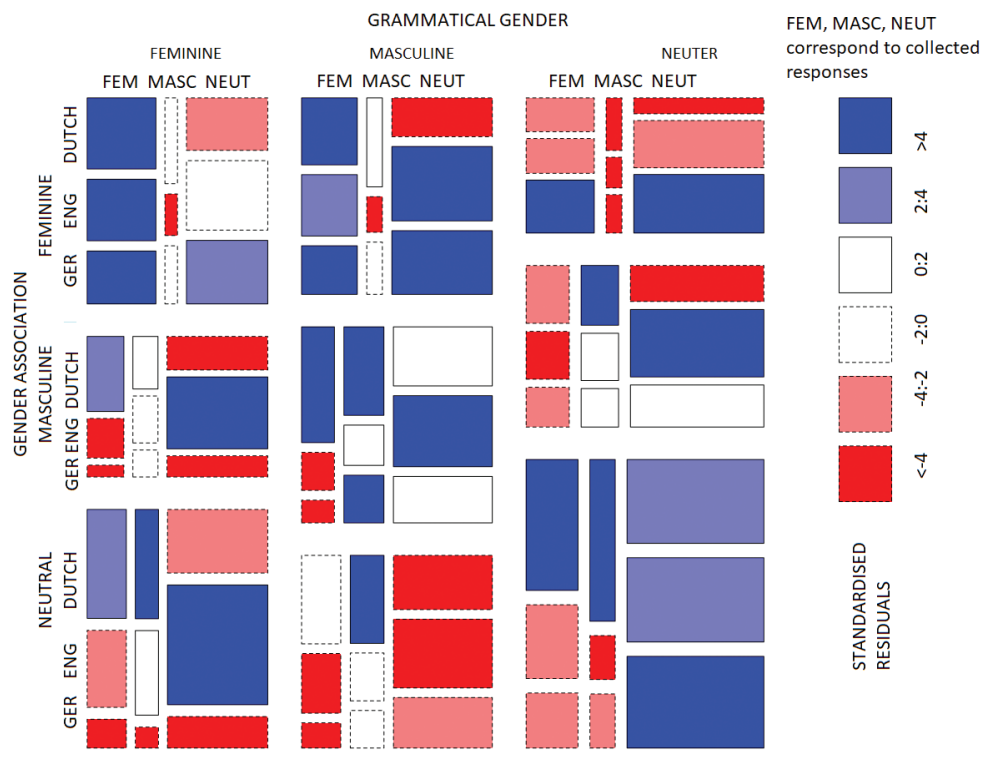

Fig. 1. Three-way interaction effect: grammatical gender $\mathrm{x}$ gender association $\mathrm{x}$ language; figure created by the authors

${ }^{6}$ The loglinear analysis presented in this research was carried out on a sample of 16,666 observations in total. Following Field et al. (2012), we used the backward elimination approach and we interpret the model with the highest order effect, which does not result in a significantly poorer fit than the saturated model. The analysis presented in this research began with building the saturated model i.e. the model including all the main and interaction effects of interest. Next, the model without the highest order interaction effect, in the case at hand the three-way interaction between grammatical gender $\mathrm{x}$ gender association $\mathrm{x}$ language, was built. This model was compared to the saturated model. A log likelihood test on model comparison showed that the model without the three-way interaction is a significantly poorer fit than the saturated model (Delta $=46.1308$; $\mathrm{df}=16 ; \mathrm{p}<0.00001$ ). This means that removing the three-way interaction effect from the model resulted in a worse fit with respect to the data. Accordingly, this means that the model that best fits the data is the one which retains the three-way interaction effect, i.e. the final model presented in this research. 


\section{Discussion}

The discussion of the results is organised by language. For each language, only significant effects are discussed.

\section{In German:}

The combination of neuter gender and neutral gender associations gave rise to significantly more adjective collocations being evaluated by our respondents as gender neutral. No significant effects are found for feminine and masculine nouns associated neutrally. This may be taken to indicate that grammatical gender alone plays a significant role only in the case of neuter nouns.

The combination of masculine gender and masculine associations caused significantly more adjective collocations to be evaluated by our respondents as stereotypically associated with masculine gender features. In other words, we observed a positive correlation between grammatical gender and stereotypical gender associations in German. Additionally, there was a negative correlation between masculine grammatical gender and feminine gender associations. This means that the participants significantly avoided feminine-related adjectival associations of masculine nouns stereotypically associated with feminine features. In the case of a mismatch between the feminine grammatical gender and masculine gender associations, participants significantly avoided feminine-related and neutral adjectival associations.

The combination of neuter gender and feminine gender associations of nouns resulted in significantly more feminine and neutral adjectival associations, as well as the avoidance of masculine adjectival associations. This indicates that both neuter grammatical gender and feminine gender associations play a role in gender perception of inanimate nouns.

The combination of masculine gender and feminine gender associations of nouns gave rise to significantly more neuter and feminine adjectival associations. This is a clear effect of stereotypical feminine gender associations, which turned out to influence gender adjectival associations more than masculine grammatical gender.

The combination of feminine gender and feminine gender associations of nouns gave rise to significantly more feminine adjectival associations. This means that there is a positive correlation between grammatical feminine gender and feminine gender associations. It seems that feminine gender associations of nouns have the biggest influence on gender perception of inanimate nouns in German.

In English:

There is no grammatical gender, therefore in this case we have focussed on the significant effects of gender associations of inanimate nouns only. 
In the case of neutral, masculine and even feminine-gender associated inanimate nouns, the respondents had significantly more neutral adjectival associations. This suggests that the lack of grammatical gender in English leads to a neutralisation of gender-related associations of inanimate nouns.

However, feminine-gender associated nouns in English also triggered significantly more feminine adjectival associations (but to a slightly lower degree than in German). This suggests that feminine gender associations have more influence on adjectival gender associations than masculine or neutral gender adjectival associations, even in a gender-neutral language. The latter observation receives additional support from the fact that in the case of feminine-associated nouns respondents significantly avoided masculine adjectival associations.

\section{In Standard Dutch:}

In the Netherlands there is no formal distinction between masculine and feminine gender. They became conflated into common gender, which in fact is more masculine, as was pointed out in Section 2.1.

Inanimate nouns with common and neuter gender and neutral and masculine associations resulted in a higher proportion of masculine adjectival associations. This corresponds to the fact that common gender nouns are mostly referred to by means of common and masculine pronouns, as was pointed out in Section 2.1. Interestingly, all of the inanimate nouns tested in our study were concrete (had a high degree of individuation). The fact that even neuter nouns gave rise to more masculine adjective associations corresponds nicely with the fact mentioned by Kraaikamp that common and masculine pronouns are used with referents with a high degree of individuation (concrete objects) (see Section 2.1).

By contrast, inanimate nouns with common gender which are stereotypically associated with feminine gender resulted in a higher proportion of feminine adjectival associations. This is less manifested in nouns with neuter grammatical gender stereotypically associated with feminine gender. In this case, our respondents significantly avoided neutral and masculine adjectival associations. Once again, this highlights a special role of feminine gender associations of inanimate nouns.

\section{Concluding remarks}

Our aim was to examine the impact of grammatical gender and stereotypical gender associations on the perception of inanimate nouns by testing gender associations of their human adjective collocations in German, Dutch and English. We showed that in German inanimate nouns with neuter gender (but not with feminine and masculine gender) and neutral gender associations gave rise to 
significantly more gender neutral adjective associations. This suggests that grammatical gender alone is not a decisive factor in affecting stereotypical masculine or feminine gender associations of inanimate nouns.

We have provided novel evidence in favour of the view that in German it is the combination of grammatical gender and stereotypical gender associations that has an impact on stereotypical gender-related adjective associations. More precisely, feminine nouns with feminine gender associations gave rise to significantly more feminine adjectival associations. Similarly, masculine nouns with masculine gender associations gave rise to more masculine adjective associations. However, it should be stressed that feminine gender associations of inanimate nouns seem to play a special role, since even in the case of masculine nouns with feminine gender associations there were significantly more feminine adjectival associations. Altogether, the results for German indicate that it is not grammatical gender alone but the interaction of grammatical gender and stereotypical gender associations of inanimate nouns which makes native speakers of German perceive them as being more feminine or masculine. This is in line with Chłopek's (2013) preliminary observations.

In English, a gender neutral language, inanimate nouns associated with neutral, masculine and even feminine gender caused significantly more neutral adjectival associations. This suggests that the lack of grammatical gender in English leads to a neutralisation of gender-related associations. However, we also observed a special role in English of stereotypical feminine associations of inanimate nouns. More precisely, feminine gender associations have more influence on adjectival gender associations than masculine or gender neutral adjectival associations, even in a gender-neutral language.

In Dutch, we have shown that nouns with common and neuter gender resulted in a higher proportion of masculine adjectival associations. We attribute this to the fact that common gender nouns are mostly referred to by means of the masculine pronoun hij in Standard Dutch in the Netherlands. We also show that the lexical semantics of nouns plays a role in the case of neuter nouns in that they seem to be perceived as masculine (as manifested in a significantly higher proportion of masculine adjective associations in the case at hand). We attribute this finding to the observation that the neuter nouns we tested were concrete objects and such nouns are referred to by means of common and masculine pronouns in Standard Dutch (see Kraaikamp 2017). We take this to indicate that common grammatical gender (which in fact is more masculine in Standard Dutch) makes native speakers of Dutch perceive the referents of inanimate common gender nouns as being more masculine. This finding is in line with the observations of Boroditsky et al. (2003). However, interestingly, we also observed a special role in Standard Dutch of stereotypical feminine gender associations of inanimate nouns. More precisely, 
we have shown that inanimate nouns with common gender and feminine associations gave rise to a higher proportion of feminine adjectival associations.

What is still to be understood is why the stereotypical perception of Dutch inanimate nouns is more sensitive to their grammatical gender than it seems to be the case in German. Also the special impact of stereotypical feminine gender associations of inanimate nouns on their being perceived as more feminine by native speakers of Dutch, German and English needs a better understanding. Another direction in which to explore the issue would be using our methodology to test adjective gender associations of inanimate nouns in northern and southern varieties of Dutch, since the latter has preserved more gender distinctions than the former. Finally, we want to stress that the results of our pilot study are preliminary, but they point to interesting new research directions which require more future research. In further research, it is necessary to test a bigger sample of participants in a more controlled manner and to collect demographic data from the participants.

\section{Bibliography}

Audring, Jenny. "Pronominal Gender in Spoken Dutch". Journal of Germanic Linguistics, vol. 18, no. 2, 2006, pp. 85-116.

Booij, Geerts. The Morphology of Dutch. Oxford University Press, 2002.

Boroditsky, Lera, et al. "Sex, syntax and semantics". Language in mind: Advances in the study of language and thought, edited by Dedre Gentner and Susan Goldin-Meadow. MIT Press, 2003, pp. 61-79.

Boutonnet, Bastien, et al. "Unconscious effects of grammatical gender during object categorization". Brain Research, vol. 1479, 2012, pp. 72-79.

Chłopek, Zofia. "Sprache und Denken, und der Begriffstransfer: Zur Perzeption des Geschlechts von geschlechtlosen Objekten durch Muttersprachler". Sprache in Wissenschaft und Unterricht (= Beiträge zur allgemeinen und vergleichenden Sprachwissenschaft, vol. 2), edited by Edyta Błachut and Adam Gołębiowski. Atut - Wrocławskie Wydawnictwo Oświatowe/Neisse Verlag, 2013, pp. 29-43.

Corbett, Greville. Gender. Cambridge University Press, 1991.

Cubelli, Roberto, et al. "The Effect of Grammatical Gender on Object Categorization". Journal of Experimental Psychology Learning Memory and Cognition, vol. 37, no. 2, 2011, pp. 449-460.

De Vogelaer, Gunther, et al. Syntactic or semantic gender agreement in Dutch, German and German learner Dutch: A speeded grammaticality judgement task. De Grueyter, 2020.

Duden. Die Grammatik: Unentbehrlich für richtiges Deutsch. 9th ed., Duden, 2016.

Eisenberg, Peter. Grundriss der deutschen Grammatik, vol. 1: Das Wort. 3rd ed., J.B. Metzler, Part of Springer Nature - Springer-Verlag GmbH, 2006.

Field, Andy, et al. Discovering statistics using R. SAGE Publications, 2012.

Geerts, Guido. Genus en Geslacht in de Gouden Eeuw: Een bijdrage tot de studie van de nominale klassifikatie en daarmee samenhangende adnominale flexievormen en pronominale verschijnselen in Hollands taalgebruik van de zeventiende eeuw. Belgisch Interuniversitair Centrum Voor Nederlandistiek, 1966. 
Gygax, Pascal M., et al. "A Language Index of Grammatical Gender dimensions for those interested in the impact of grammatical gender on the way we perceive women and men". Frontiers in Psychology, vol. 10, 2019, pp. 1-6.

Haertlé, Izabella. "Does Grammatical Gender Influence Perception? A Study of Polish and French Speakers". Psychology of Language and Communication, vol. 21, no. 1, 2017, pp. 386-407.

Jakobson, Roman. "On Linguistic Aspects of Translation". On Translation, edited by Reuben A. Brower. Oxford University Press, 1966, pp. 232-239.

Kilgarriff, Adam, et al. "The Sketch Engine: ten years on". Lexicography, vol. 1, 2014, pp. 7-36.

Konishi, Toshi. "The semantics of grammatical gender: A cross-cultural study". Journal of Psycholinguistic Research, vol. 22, no. 5, 1993, pp. 519-534.

Kraaikamp, Margot. Semantic versus lexical gender. Synchronic and diachronic variation in Germanic gender agreement. LOT, Utrecht University, 2017.

Mickan, Anne, et al. "Key is a llave is a Schlüssel: A failure to replicate an experiment from Boroditsky et al. 2003". Yearbook of the German Cognitive Linguistics Association, vol. 9, no. 1, 2014, pp. 39-50.

Ripley, Brian, et al. MASS: Functions and datasets to support Venables and Ripley. Modern Applied Statistics with S. Springer-Verlag, 2017.

Segel, Edward, and Lera Boroditsky. "Grammar in art". Frontiers in Psychology, vol. 1, 2011, pp. 1-3.

Sera, Maria D., et al. "Grammatical and conceptual forces in the attribution of gender by English and Spanish speakers". Cognitive Development, vol. 9, no. 3, 1994, pp. 261-292.

Slobin, Dan I. "From 'thought and language' to 'thinking for speaking"'. Studies in the social and cultural foundations of language, no. 17: Rethinking linguistic relativity, edited by John J. Gumperz and Stephen C. Levinson. Cambridge University Press, 1996, pp. 70-96.

Van Haeringen, Coenraad Bernardus. Nederlands tussen Duits en Engels. Servire, 1956.

Vigliocco, Gabriella, et al. "Grammatical Gender Effects on Cognition: Implications for Language, in: Learning and Language Use". Journal of Experimental Psychology: General 2005, vol. 134, no. 4, 2005, pp. 501-520.

Whorf, Benjamin Lee. Language, thought, and reality: selected writings. Technology Press of Massachusetts Institute of Technology, 1956.

Williams, Adina, et al. "On the Relationships Between the Grammatical Genders of Inanimate Nouns and Their Co-Occurring Adjectives and Verb". Transactions of the Association for Computational Linguistics, vol. 9, 2021, pp. 139-159. 
Appendix: German, Dutch and English nouns used in our study

\begin{tabular}{|c|c|c|c|}
\hline $\begin{array}{c}\text { Gender } \\
\text { associations }\end{array}$ & German & Dutch & English \\
\hline feminine & die Bluse & de bloes & blouse \\
\hline feminine & die Tasche & de tas & bag \\
\hline feminine & die Wimper & de wimper & eyelash \\
\hline feminine & die Halskette & de halsketting & necklace \\
\hline feminine & die Blume & de bloem & flower \\
\hline masculine & die Axt & de bijl & axe \\
\hline masculine & die Pfeife & de pijp & pipe \\
\hline masculine & die Rüstung & de bepantsering & armour \\
\hline masculine & die Uniform & de uniform & suit \\
\hline masculine & die Krawatte & de stropdas & tie \\
\hline neutral & die Lampe & de lamp & lamp \\
\hline neutral & die Straße & de straat & street \\
\hline neutral & die Flasche & de fles & bottle \\
\hline neutral & die Dose & de doos & can \\
\hline neutral & die Brücke & de brug & bridge \\
\hline feminine & der Büstenhalter & de beha & bra \\
\hline feminine & der Ring & de ring & ring \\
\hline feminine & der Schleier & de sluier & veil \\
\hline feminine & der Rock & de rok & skirt \\
\hline feminine & $\begin{array}{l}\text { der Lidstrich, } \\
\text { der Eyeliner }\end{array}$ & de eyeliner & eyeliner \\
\hline masculine & der Schraubenzieher & de schroevendraaier & screwdriver \\
\hline masculine & der Bart & de baard & beard \\
\hline masculine & der Tractor & de tractor & tractor \\
\hline masculine & der Motor & de motor & engine \\
\hline masculine & der Hammer & de hamer & hammer \\
\hline neutral & der Stuhl & de stoel & chair \\
\hline neutral & der Schuh & de schoen & shoe \\
\hline neutral & der Zaun & de omheining & carpet \\
\hline neutral & der Zweig & de tak & branch \\
\hline neutral & der Berg & de berg & mountain \\
\hline feminine & das Bügeleisen & het strijkijzer & iron \\
\hline feminine & das Kopftuch & het hoofddoek & headscarf \\
\hline feminine & das Armband & het armbandje & bracelet \\
\hline
\end{tabular}




\begin{tabular}{|c|c|c|c|}
\hline feminine & das Tischtuch & het tafelkleed & tablecloth \\
\hline feminine & das Juwel & het juweel & jewel \\
\hline masculine & das Rad & het wiel & wheel \\
\hline masculine & das Hemd & het hemd & shirt \\
\hline masculine & das Bier & het bier & beer \\
\hline masculine & das Schwert & het zwaard & sword \\
\hline masculine & das Flugzeug & het vliegtuig & airplane \\
\hline neutral & das Haus & het huis & house \\
\hline neutral & das Bild & het beeld & painting \\
\hline neutral & das Buch & het boek & book \\
\hline neutral & das Bett & het bed & bed \\
\hline neutral & das Auge & het oog & eye \\
\hline
\end{tabular}

Table 4. Appendix: German, Dutch and English nouns used in the study; table created by the authors 